\title{
Fiber Bragg Grating Sensors-Based In Situ Monitoring and Safety Assessment of Loess Tunnel
}

\author{
Jinxing Lai, ${ }^{1}$ Junling Qiu, ${ }^{1}$ Haobo Fan, ${ }^{1}$ Qian Zhang, ${ }^{2}$ Zhinan Hu, \\ Junbao Wang, ${ }^{3}$ and Jianxun Chen ${ }^{1}$ \\ ${ }^{1}$ School of Highway, Chang'an University, Xian 710064, China \\ ${ }^{2}$ School of Civil Engineering, Shijiazhuang Tiedao University, Shijiazhuang 050043, China \\ ${ }^{3}$ School of Civil Engineering, Xi'an University of Architecture and Technology, Xian 710055, China \\ Correspondence should be addressed to Jianxun Chen; chenjx1969@chd.edu.cn
}

Received 28 January 2016; Revised 1 May 2016; Accepted 17 May 2016

Academic Editor: Zhenhua Zhu

Copyright (C) 2016 Jinxing Lai et al. This is an open access article distributed under the Creative Commons Attribution License, which permits unrestricted use, distribution, and reproduction in any medium, provided the original work is properly cited.

\begin{abstract}
Compared with electrical strain gauges, fiber Bragg grating (FBG) sensing technology is a relatively novel method for tunnel structural health monitoring, which has a number of advantages including high accuracy, multiplexing, electromagnetic interference resistance, and good repeatability. In order to study the internal force of the tunnel liner and detect the potential safety hazards, series of strain monitoring tests of a loess tunnel, taking into account the complex stress and strain variation of the loess during tunnelling, were performed by employing the tandem linear FBG sensor arrays controlled by the wavelength division multiplexing (WDM) technology. The concrete strain has obvious linear characteristics over time in the early stage and then gradually tends to a stable value. Moreover, after the necessary temperature compensation, loess tunnel structure safety was assessed through the analysis of real-time strain and internal force of the liner concrete, and the FBG monitoring data and safety assessment results indicate that the safety factors of various liner sections all meet the code requirements, which verify the safety and stability of the tunnel liner structure. The FBG sensors-based in situ monitoring technology can be well applied in the loess tunnel structure safety assessment.
\end{abstract}

\section{Introduction}

Geotechnical structures, such as dam, slope, foundation, and tunnel, are frequently subjected to dynamic loadings for instances seismic and construction loadings, which may result in structure deterioration or failure. Construction measurement plays an essential role in tunnel safety assessment, which provides not only in situ construction safety information but also valuable data for theory and practice research [1-3]. In the last decades, various monitoring instruments had been developed for tunnelling, such as laser displacement sensors (LDS), linear variable differential transformer (LVDT), dial gauges, and vision based systems [4-6]. Conventional monitoring sensors, mostly based on resistance type, inductance type, and vibrating wire type [7], are either unsuitable for remote real-time monitoring or too bulky or sophisticated for mass application in the structural health monitoring (SHM) of tunnel structures [8-10]. FBG sensors have commenced in safety assessment of geotechnical structures, which features small size, light weight, nonconductivity, fast response, resistance to corrosion, higher temperature capability, and immunity to electromagnetic noise and radio frequency interference [11-15]. In 1990, Mendez et al. [16] firstly employed FBG sensors for the safety assessment of reinforced concrete structure, and, since then, the monitoring technology using FBG sensors has been developed rapidly. Besides, FBG sensors are encoded by wavelength, making the signal of FBGs immune to power fluctuations along the optical path, which have been shown to measure local and directional strains with accuracy compared to the conventional strain gauges and extensometers [17, 18]. Nowadays, FBG sensors have attracted much interest and they are being used in numerous applications, especially in tunnel construction monitoring and bridge health assessment [19, 
20]. Sun et al. [21] believed that smart sensing technologies are now currently available and reviewed the application of smart materials/sensors for the SHM of civil engineering structures. Ye et al. $[22,23]$ presented a summary of the basic principles of various optical fiber sensors, innovation in sensing, and computational methodologies. Lai et al. [24] established a wireless sensor network (WSN) to monitor the effect of the blast-induced vibration on the structure of existing tunnel. Tondini et al. [25] investigated the capabilities of FBG sensors in monitoring the inelastic response of new circular concrete tunnel liners, subjected to seismic events. In order to compare the thermocouple readings with the readings of a FBG sensor, Lönnermark et al. [26] performed fire experiments in a model-scale tunnel, which shows that the temperature measured by the FBG sensor is closer to the "true" gas temperature than is the case for any of the thermocouples used in these tests. According to the features of structure strain and temperature distribution in tunnel, Li et al. [27] developed a metal groove encapsulating technique for the bare FBG to measure the surface strain of test structure. Roveri et al. [28] presented the results of a field trial with a FBG sensor array system for the realtime monitoring of railway traffic and for the SHM of both the railway track and train wheels. Weng et al. [29-31] developed a FBG-based sensor network to monitor the strain distributions in the pavement structure, axial stress of tunnel anchor, and foundation settlement; moreover, the centrifugal model test was performed with an improved packaging and installation method for the quasi-distributed sensor system. In view of the aforementioned studies, in situ monitoring through installation of sensors is a widely used method for the investigation into the mechanical properties and strain changes of tunnel liner with better accuracy and reliability [32].

Loess, which is derived from unconsolidated materials, is sensitive to sliding upon wetting and being broken down due to its metastable structure. Loess has a significant character of randomly open and loose particle with high porosity [34]. When a large span tunnel or underground space is constructed in loess ground, it inevitably disturbs the in situ stress field and then causes large ground displacements. Generally, loess is a multiphase porous medium and develops complex stress and strain variation while executing a tunnelling project. And the stability of tunnel liner has a direct effect on the construction safety [35]. Accordingly, through in situ monitoring of liner concrete strain in the typical cross sections, the real-time data can be obtained during tunnelling [36]. Selecting an appropriate sensor for the strain monitoring of the tunnel liner in loess stratum is important for the safety construction and operation of the tunnel. FBG sensing technology combined with remote transmission and automatic data processing has provided new methods for the in situ monitoring and safety assessment of the tunnels under complicated geological conditions. However, the application of FBG sensors to the loess tunnel is rarely reported. In this study, based on a loess tunnel in Northwest China, a series of in situ monitoring of strain and stress in typical cross sections were conducted by employing quasi-distributed FBG sensors; also the safety of tunnel liner structure was evaluated.
The presented in situ monitoring and safety assessment of tunnel liner structure in loess stratum have the potential to be widely applied to the evaluation of the risk associated with underground excavation.

\section{Principle of the FBG Sensor}

In 1978, Hill et al. [37] first reported the formation of refractive index gratings in germanosilicate fiber by sustained exposure of the core to the interference pattern of oppositely propagating modes and presented photosensitivity characteristics of the fiber. Employing the holographic dry technology, Meltz et al. [38] obtained the first grating with the resonant wavelength of $820 \mathrm{~nm}$ in 1989. The grating is formed in photorefractive germanosilicate fiber by being exposed to a coherent two-beam UV interference pattern, which provides a new way for making quasi-distributed measurements of temperature and strain by monitoring the shift of the Bragg wavelength in the sensing regions, each being individually tuned to a distinct wavelength. The change of refractive index of fiber core is obvious after the strong ultraviolet irradiation [39]. For all incident lights, only the light with certain wavelength can be reflected and returned by the FBG. Figure 1 shows the composition and measurement principal of FBG sensor system. The Bragg grating central wavelength has good response to external temperature, strain, and so forth [40-42], as shown in

$$
\frac{\Delta \lambda_{B}}{\lambda_{B}}=\left[\frac{1}{n} \xi+\alpha_{f}\right] \Delta T+\left(1-P_{e}\right) \Delta_{\varepsilon},
$$

where $\Delta \lambda_{B}$ is the displacement of wavelength, $\lambda_{B}$ is the Bragg wavelength, $n$ is the effective reflective index of fiber core, $\xi=(1 / n)(d n / d T)$ is the thermooptic coefficient of fiber, $\Delta T$ is the temperature increment, $\alpha_{f}=(1 / \Lambda)(d \Lambda / d T)$ is the thermal expansion coefficient of fiber, $\Lambda$ is the grating period, $P_{e}=(1 / n)(d n / d \varepsilon)$ is the effective elastooptical coefficient, and $\varepsilon$ and $\Delta \varepsilon$ are the axial strain and the strain increment, respectively.

Combined with the demands and characteristics of monitoring projects, FBG sensors can be placed on the surface of components or buried in the structures to monitor the FBG wavelength change and obtain the stress and strain. The wavelength change of the FBG sensor is influenced by the strain and the temperature. And the cross-sensitivity influence of strain and temperature is directly related to the accuracy of measurement results. To avoid the influence of temperature change in the process of strain measuring, the temperature compensation is usually performed by using the FBG temperature sensor in the same environment. Accordingly, the temperature induced wavelength shift can be excluded in data processing, and the wavelength change induced by the temperature compensation can be expressed as follows [42]:

$$
\begin{aligned}
\Delta \lambda_{B}= & \lambda_{B}\left\{1-\frac{n_{\mathrm{eff}}^{2}}{2}\left[P_{12}-v\left(P_{11}+P_{12}\right)\right]\right\} \\
& +\lambda_{B}(\alpha+\xi) \Delta T
\end{aligned}
$$




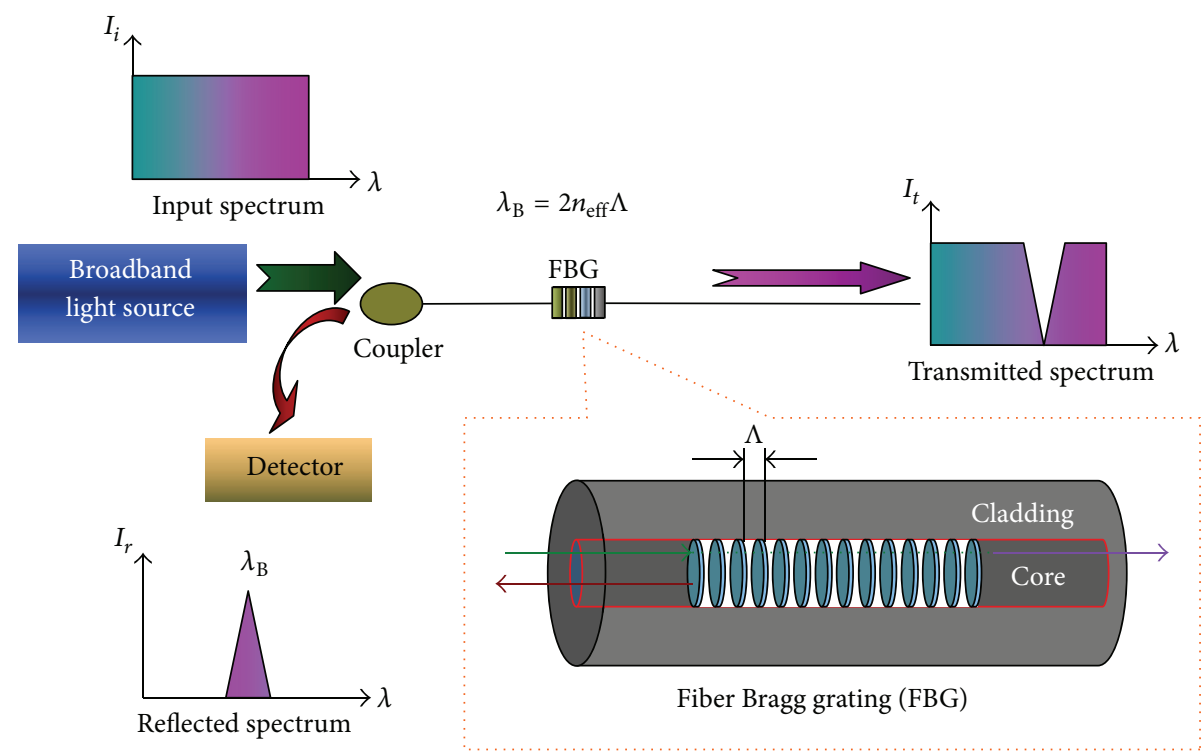

FIGURE 1: Measurement principal of the FBG sensor [22, 23].

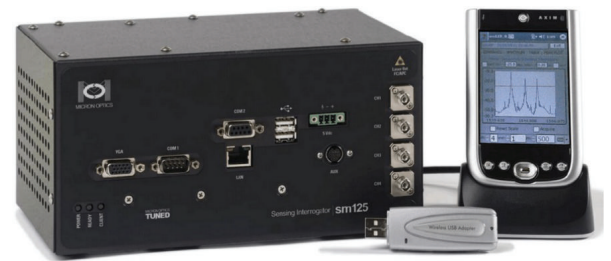

FIgURE 2: A front panel view of the SM125 optical sensing interrogator [33].

where $P_{12}$ and $P_{11}$ are the elastooptical coefficients of the single-mode fiber, $v$ is the Poisson ratio of the fiber material, and $n_{\text {eff }}$ is the effective refractive index of the fiber core.

\section{FBG Selection and Array Design of Quasi-Distributed FBG Sensors}

3.1. FBG Sensor and Data Acquisition System. The monitoring system is mainly composed of four parts, which are FBG sensor, signal transmission, acquisition system, and data processing system. In FBG sensor data acquisition system, the SM125-500 optical sensing interrogator produced by the United States MOI (Optics Micron, Inc.) is a four-channel Fabry-Perot filter with full spectrum display [33], as shown in Figure 2, which is suitable for long-term monitoring in severe environment. The wavelength is $1510-1590 \mathrm{~nm}$. The stability and accuracy of wavelength is $1 \mathrm{pm}$. The operating temperature is $0 \sim 50^{\circ} \mathrm{C}$. The interrogator can show the optical properties with bandwidth of $1-2 \mathrm{GHz} / 3 \mathrm{~dB}$. The dynamic range is $50 \mathrm{~dB}$ and the scan frequency is $1 \mathrm{~Hz}$. The parameters of the interrogator are detailed in Table 1. The SMF28 fiber is coated with acrylate, the resolution of the fiber is $0.25 \pm$ $0.05 \mathrm{~nm}$, and the bending radius is $25 \mathrm{~mm}$. The temperature sensitivity coefficient of Bragg grating is $10.9 \mathrm{pm} /{ }^{\circ} \mathrm{C}$. In order to minimize the impact of explosion and casting of liner concretes on the fiber during tunnelling, intermediate
TABLE 1: Specifications for the SM125-500 [33].

\begin{tabular}{lc}
\hline Specifications & SM125-500 \\
\hline Number of optical channels & $4(8 \& 16$ available $)$ \\
Wavelength characters & $1510-1590 \mathrm{~nm}$ \\
Range & $1 \mathrm{pm}$ \\
Accuracy & $1 \mathrm{pm}$ \\
Stability & $0.5 \mathrm{pm}$ at full speed and $0.2 \mathrm{pm}$ \\
Repeatability & with 10 averages \\
Dynamic range & $50 \mathrm{~dB}$ \\
Scan frequency & $1 \mathrm{~Hz}(2$ and $5 \mathrm{~Hz}$ available $)$ \\
Typical sensor spacing & $>2 \mathrm{x}$ sensor bandwidth \\
Optical connectors & $\mathrm{FC} / \mathrm{APC}(\mathrm{E} 2000$ available $)$ \\
Operating temperature & $0^{\circ}$ to $50^{\circ} \mathrm{C}$ \\
\hline
\end{tabular}

bonding layer and capillary steel casing pipe are used for protection.

3.2. Temperature Calibration for the FBG Sensor. Since the FBG sensor is sensitive to the temperature change in the liner concrete, temperature calibration for sensors is required. Four FBG strain sensors with different central wavelengths 


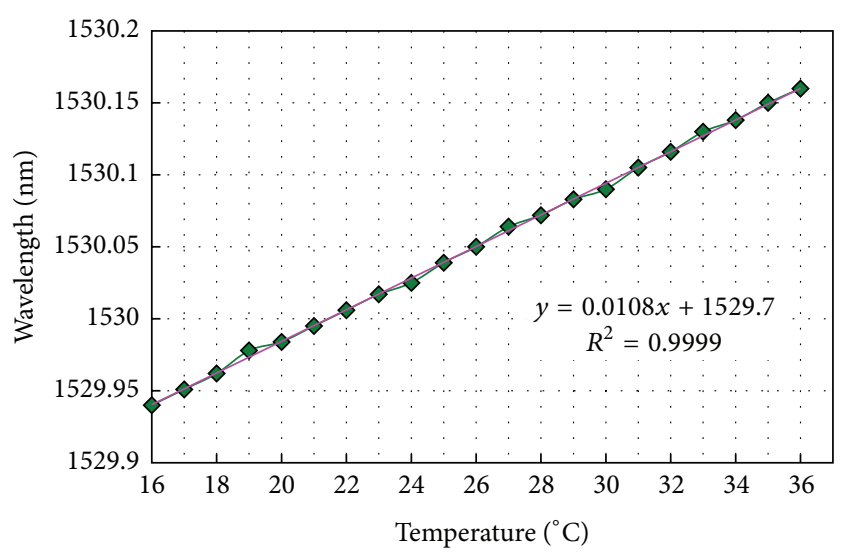

FIGURE 3: Temperature sensitivity of the embedded FBG sensor with a central wavelength of $1529 \mathrm{~nm}$.

were selected, and the mercury thermometer with accuracy of $0.05^{\circ} \mathrm{C}$ was chosen for temperature measurement. Then the temperature calibration was performed by using water bath method. Four sensors were, respectively, placed in two calibrated water channels with the adjusted temperature field of $16-38^{\circ} \mathrm{C}$. Temperature and the corresponding FBG wavelength were collected, and their typical response curve is shown in Figure 3.

Results (cf. Figure 3) indicate that the FBG wavelength has a linear relationship to the temperature. Based on the regression analysis, response relationship of wavelength $(\lambda)$ to temperature $(T)$ is obtained as follows:

$$
\lambda_{B}=0.0108 T+1529.7 .
$$

The correlation coefficient of the regression formula is 99.99\%. The experiments on four FBG sensors indicate that the average increment of wavelength is $10.8 \mathrm{pm}$ with the temperature rise of $1^{\circ} \mathrm{C}$; that is, the temperature sensitivity coefficient of the $\mathrm{FBG}$ sensor is $10.8 \mathrm{pm} /{ }^{\circ} \mathrm{C}$.

3.3. Strain Calibration for the FBG Sensor. Strain calibration is required before the installation of FBG sensors. Firstly, for easy installation with high survival rate, a bare fiber was fixed on the cold-drawn round steel wire with a diameter of $0.9 \mathrm{~mm}$, after which the steel wire was placed in concrete testing mold with a size of $150 \mathrm{~mm} \times 150 \mathrm{~mm} \times 150 \mathrm{~mm}$. The FBG sensor was located at the middle of testing mould, and the direction of the fiber was parallel to the side of mould. One end of the fiber was held out from the side along steel wire, and then C20 concrete was poured. Removal of mould should be performed after the initial setting of concrete (about 8 hours). Finally, these samples were placed in the universal testing machine for the compression experiment. Based on regression analysis, the response expression of strain-wavelength can be obtained as (4), and the regression curve is visible in Figure 4. The correlation coefficient is $99.99 \%$, and the strain sensitivity coefficient is $-0.003 \mathrm{~nm} / \mu \varepsilon$ :

$$
\lambda_{B}=-0.0003 \mu \varepsilon+1527.7 .
$$

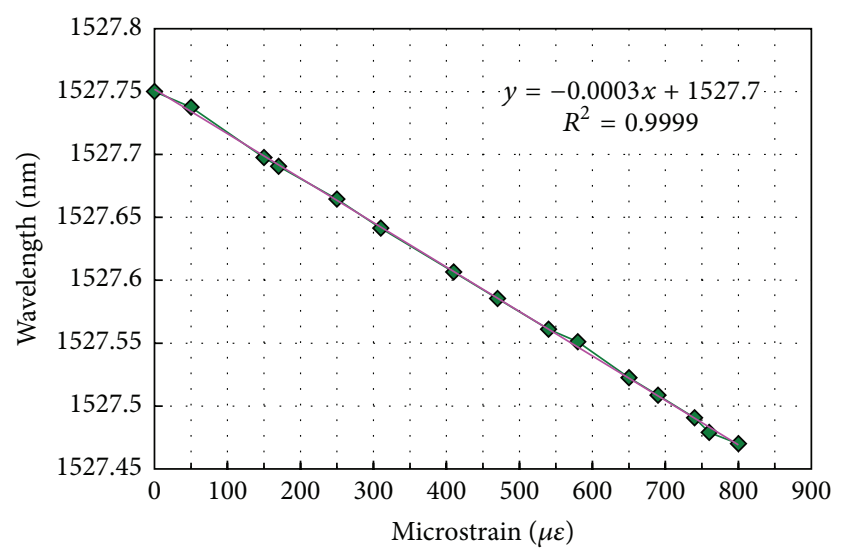

FIGURE 4: Strain sensitivity coefficient of the FBG sensor in concrete.

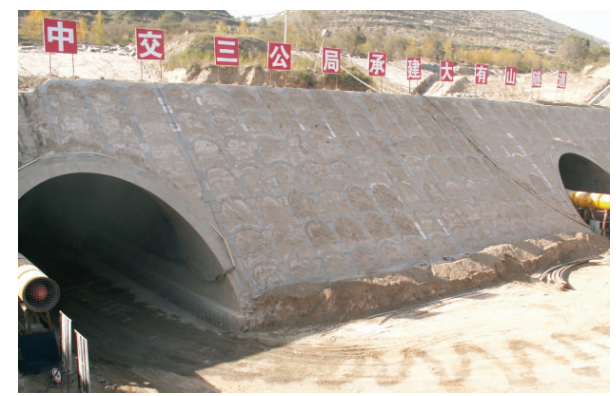

FIGURE 5: Construction site of Dayoushan Tunnel.

\subsection{FBG Sensor Layout in Dayoushan Tunnel}

3.4.1. Project Overview. The Dayoushan Tunnel, as shown in Figure 5, is a critical control engineering of Xining transit highway (Dandong-Lhasa), which is located at the northwest loess tableland area of China. Dayoushan Tunnel is the closely spaced twin-tunnels, and the length of right tunnel is $2,535 \mathrm{~m}$ with the stake number of $\mathrm{k} 2+655 \sim \mathrm{k} 5+190$ and the length of left tunnel is $2,560 \mathrm{~m}$ with the stake number of $\mathrm{k} 2+655 \sim \mathrm{k} 5+215$. The ground (within $60 \mathrm{~m}$ ) typically consists of three types of high compressed soil, including $Q_{4}$ loess, late Pleistocene eolian loess, and artificial fill with a collapse depth of $10 \sim 20 \mathrm{~m}$. The rock mass around the tunnel is mainly $Q_{4}$ collapsible loess with a rock mass grade of $\mathrm{V}$.

3.4.2. Installation Scheme for FBG Sensor Arrays. Considering the construction progress and the disease situation of the Dyoushan Tunnel, eight representative test sections of the right tunnel were selected to install the embedded FBG sensors, as shown in Figure 6. Typical points, including vault, spandrel, and hance in the tunnel, were selected to monitor the change of strain and internal force of the liner concrete. Moreover, a FBG temperature compensation sensor was installed in the vault of each section to monitor the temperature change of the liner structure. The quasidistributed FBG strain sensor monitoring network was laid out as Figure 7. 


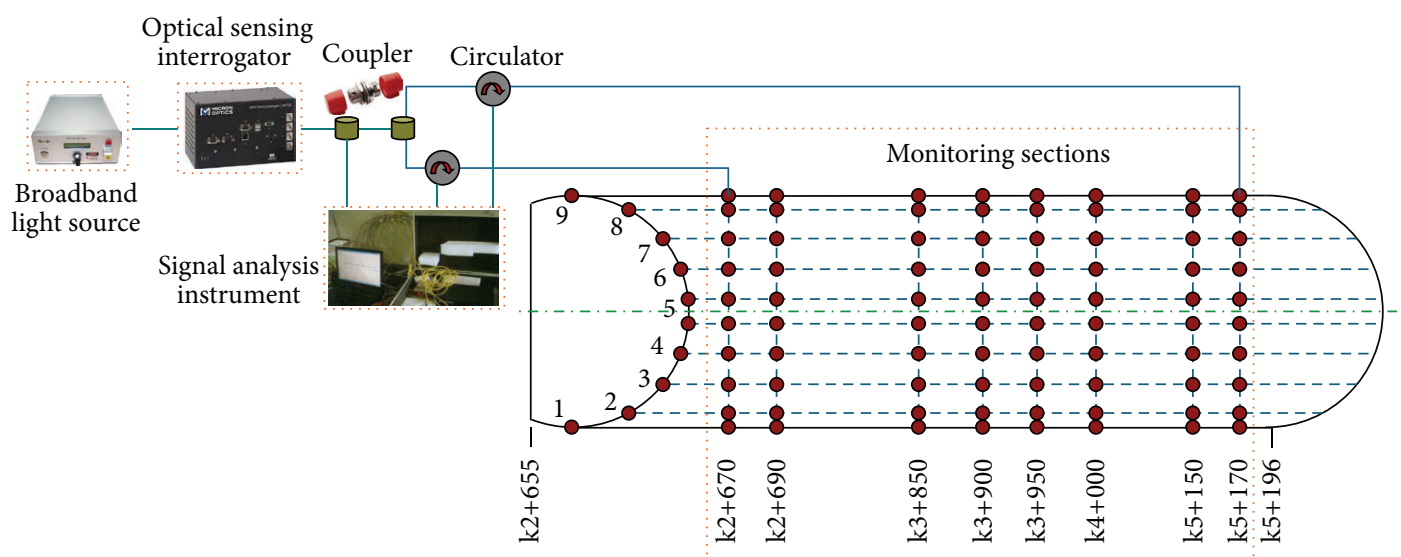
(1) Right arch foot
(9) Right arch foot
(2) Right sidewall
(8) Right sidewall
(3) Right hance
(7) Right hance
(4) Right spandrel
(6) Right spandrel
(5) Vault
(5) Vault

Figure 6: In situ test scheme of the Dayoushan Tunnel.

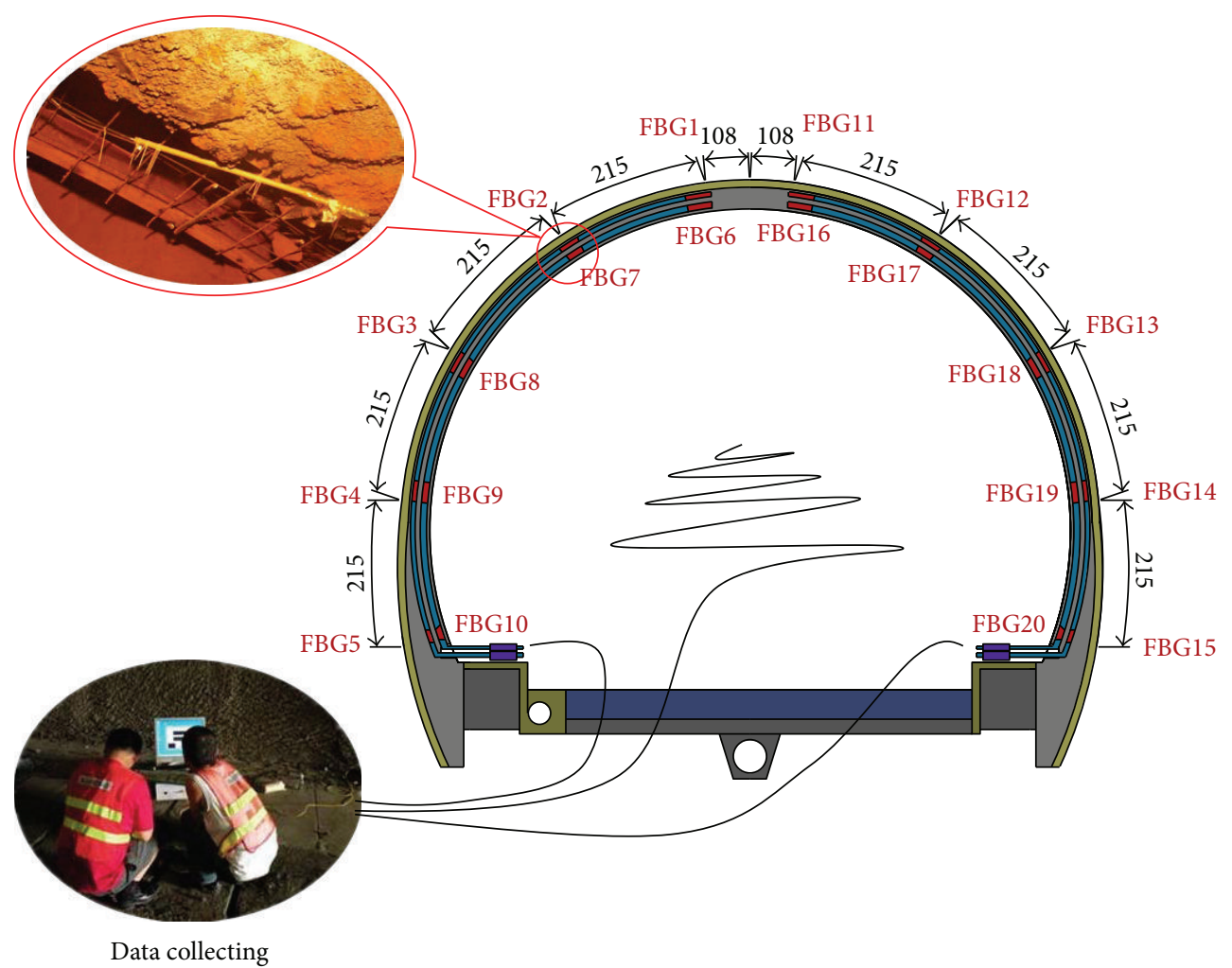

FigURE 7: Layout of the FBG strain sensors.

The length of the fiber as well as the installation position of FBG sensors was determined according to the size of tunnel cross section. For each test section, two layout methods could be employed: only using an independent fiber for the connection and signal transmission, or using two independent fibers according to the left and right sides of the tunnel cross section. In addition, employing the
WDM technology, the coded FBG sensors with different wavelengths were cascade to each fiber. Then each test section constitutes 1 2 independent linear arrays. During the actual installation, four fibers were symmetrically laid on a test section; that is, two fibers were laid on each side of the testing section. Moreover, to fix the fiber, two plain round bars with the diameter of $12 \mathrm{~mm}$ were erected at the inner and 


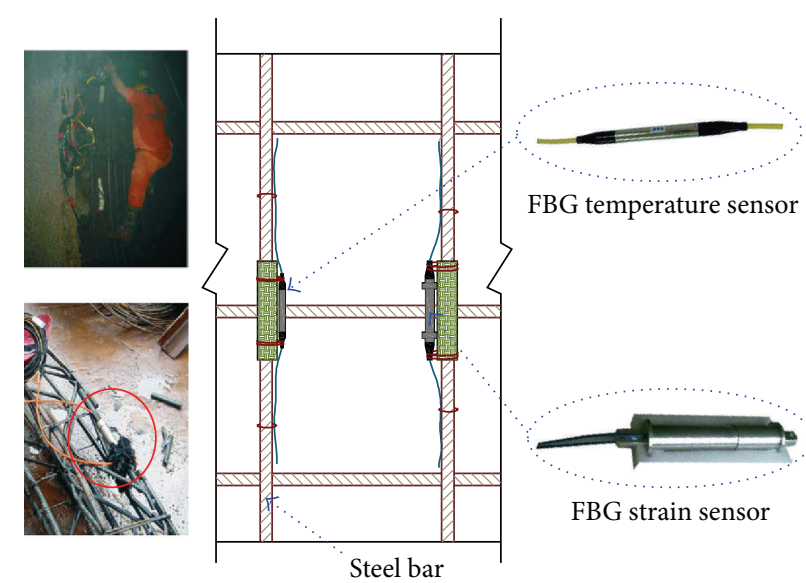

Figure 8: A schematic view for the installation of FBG sensors.

outer sides behind the tunnel secondary liner trolley, and the space between the inner side and outer side was $38 \mathrm{~cm}$ (inner side was the direction of tunnel clearance; outer side was the direction of rock mass). Then the fibers were tightened and fixed along the steel bar using the lacing wire (cf. Figure 8). FBG temperature sensors and FBG strain sensors were installed near the steel bar with cushion layers; therefore the cooperation deformation of the FBG strain sensor and the concrete strain could be achieved. Additionally, in order to ensure the normal operation of the FBG sensors, the necessary protective measures should be taken in the process of pouring concrete. To avoid the damage from construction, two wooden cases were fixed at each side of the back of trolley. The fiber was put into wooden case after being enveloped by the hose. And the fiber was placed into the case for protection after each data collection. It is important to note that the integrity of FBG should be given overall inspection before embedment to ensure the reliability of test specimens.

\section{Internal Force Analysis and Safety Assessment of Liner Structure}

Previous research has shown that the adiabatic heating value reaches the maximum after $2 \sim 4 \mathrm{~d}$ of concrete pouring [43]. Generally, the heating-up value induced by hydration is exponentially related to the concrete age. To reduce the cross impact of hydration heat of cement on the FBG, FBG inspection data of cross sections were collected each morning and afternoon five days after the concrete pouring. The reflected spectrum was collected and analyzed preliminarily using the remote software of the SM125 optical sensing interrogator [33]. Specifically, considering the influence of the significant cement hydration, the reflected spectrum with the two channels on the 11th day is given in Figure 9. The reflected spectrum is continuous with strong signals, and abnormal sidelobes are not seen in shortwave direction. In general, these FBG sensors have strong reflected signals in normal operating state.

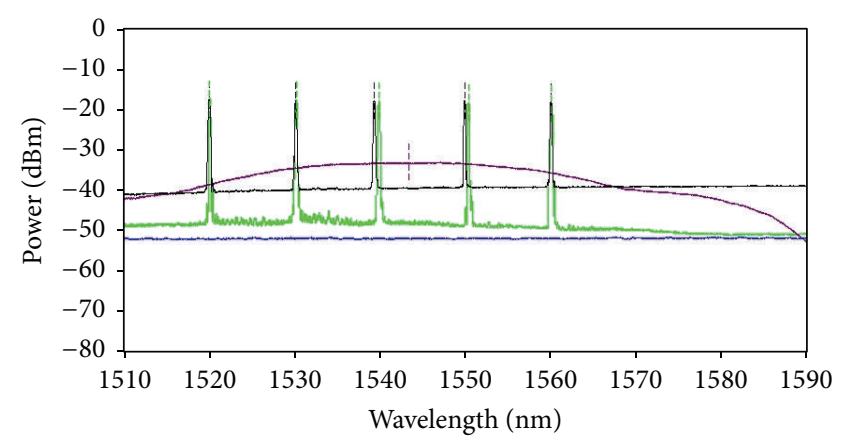

FIGURE 9: Reflected spectrum with two channels on the 11th day [33].

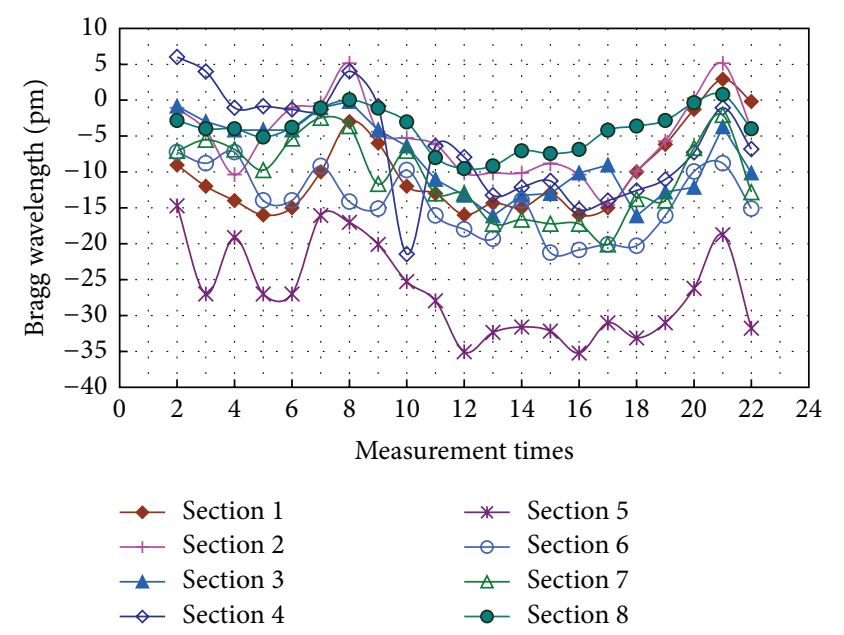

FIGURE 10: Wavelength change of the FBG temperature sensor with different measurement times.

4.1. Temporal Strain Features of Liner Concrete. The change of environment temperature can cause the Bragg wavelength shift, which directly impacts the accuracy of the strain monitoring results. Generally, for the FBG sensor, the temperature sensitivity is about 10 times of the strain sensitivity. Therefore, the influence of the temperature change should be considered for the FBG sensors-based strain monitoring. In order to detect the influence of the temperature difference on the Bragg wavelength change inside the tunnel, each test section had been continuously monitored for 24 hours (with the mean time interval of $1 \sim 2 \mathrm{~h}$ ). Figure 10 shows the wavelength change of the FBG temperature sensor with different measurement times in the eight test sections. It can be seen that the range of wavelength change is mainly $-40 \sim 10 \mathrm{pm}$ in one day. With the decrease of temperature, the wavelength change decreases accordingly, while the wavelength change increases gradually with the temperature increasing.

Through comparative analysis, the typical test section $\mathrm{K} 3+900$ was selected to investigate the internal force character and the safety assessment of the liner structure. For the FBG temperature sensor, considering the heat induced by the cement hydration, the liner structure temperature increased greatly at the initial stage (within about 15 days). The structure temperature decreased gradually and then tended to be constant when the hydration heat of cement was finished, 


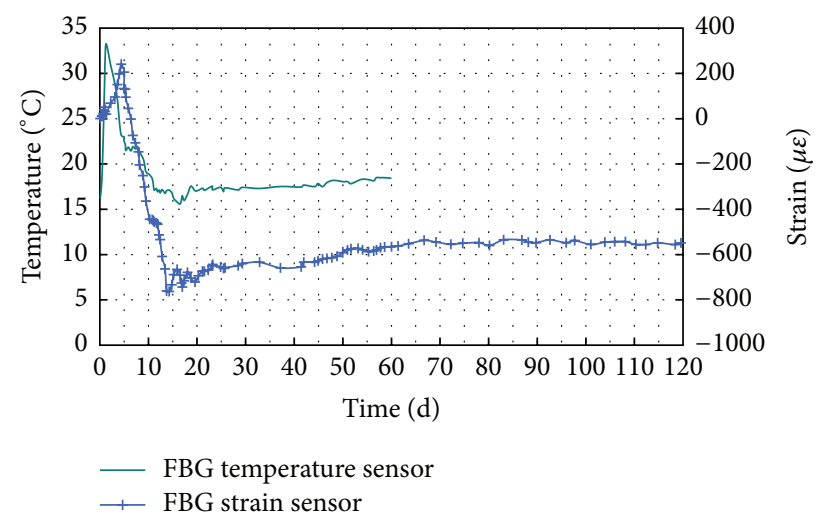

FIGURE 11: Corresponding relation between the temperature change and the strain change.

Time (d)

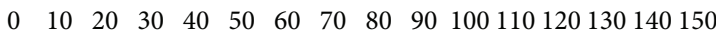

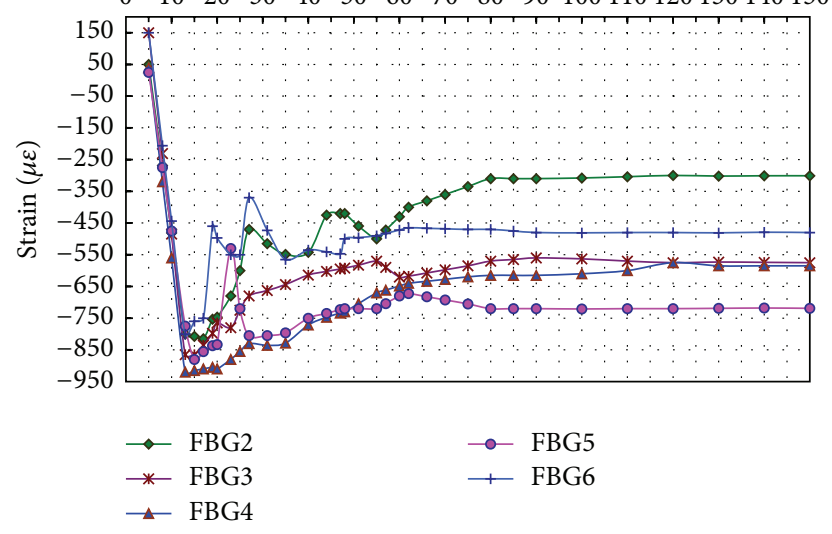

FIgURE 12: Tunnel liner concrete strain versus time.

as shown in Figure 11. Afterwards, the structure temperature changed with the environment temperature. Because the environment temperature is relatively stable during the tunnelling, the structure temperature increased slightly with time. For the FBG strain sensor, the measured internal strain of the liner concrete changed significantly at the initial stage, mostly due to the hydration heat of cement. The temperature compensation that took into consideration the measured wavelength shift was performed for the FBG strain sensors, and then the strain can be calculated accordingly. In the test sections, through the necessary temperature compensation, the temporal stain feature curves (cf. Figure 12) at inner and outer sides of liner concrete could be presented.

From nearly 5 months of monitoring data, the temporal stain feature curves tend to be stable gradually, and the change of the central wavelengths of FBG sensors is stable without large discrete shift, which indicates the performance stability of FBG sensors. Specifically, the wavelength of the FBG temperature sensor changes greatly during the concrete pouring and then is stabilized after setting the concrete. The stable temperature is $18.2^{\circ} \mathrm{C}$, which can be regarded as the rock mass temperature. For the same section, the concrete with FBG sensors installed has similar temporal strain variation characters. Results also indicate that the compressive stress on the liner concrete has obvious linear characteristics over time in the early stage of monitoring. More specifically, the change of concrete strain is significant on the 6th day of monitoring and the change rate of concrete strain begins to decrease on the 13th day of monitoring; then the concrete strain has the characteristic of great fluctuation between the 15th day and the 80th day of monitoring. Finally, the change of concrete strain gets smaller and gradually tends to a certain value after 90th day. Moreover, the strain curves of the outer side of the liner concrete are steeper than that of the inner side, indicating that the change rate of concrete strain at the outer side of the liner concrete is relatively large. Generally, the outer side of the liner concrete is subjected by much of the rock mass pressure; therefore the strain change will be large with the disturbance of the rock mass. For the inner side of the liner concrete, the force will be shared, transferred, and dissipated because of the stress characteristics of the arch structure; that is, the strain-energy will be dissipated in the liner structure [44].

\subsection{Transverse Distribution Characteristics of the Secondary} Liner Concrete Strain. Based on the monitoring data of FBG sensors, internal force distribution of the monitoring section (see Figure 13) was obtained. Meanwhile, further investigations on the mechanical properties of the liner structure, such as axial force, shear force, bending moment, and transverse distribution, were conducted, which can comprehensively present the stress state of liner structure, judge the rationality of liner parameters, and provide theoretical basis for the design revision of tunnel liner and supporting structure.

From the axial force and bending moment presented in Figure 13 (the bending moment and axial force of symmetric section are the values in bracket), it can be seen that the liner concrete is in pressured state and the stress of monitoring points does not exceed the allowable stress of concrete. Specifically, the bending moment and the axial force of left spandrel (FBG3/FBG8) are $-34.33 \mathrm{kN} \cdot \mathrm{m}$ and $-4322.65 \mathrm{kN}$, respectively. Thus, the left spandrel is subjected to the maximum axial force. The bending moment and the axial force of left vault (FBG1/FBG6) are $74.46 \mathrm{kN} \cdot \mathrm{m}$ and $-3437.43 \mathrm{kN}$, respectively; it is the minimum axial force position. The maximum bending moment is $113.12 \mathrm{kN} \cdot \mathrm{m}$, which is located at the monitoring points FBG5/FBG10 with an axial force of $-3664.58 \mathrm{kN}$. The minimum bending moment is $-34.33 \mathrm{kN} \cdot \mathrm{m}$, located at the spandrel. According to calculated results, the secondary liner internal force is symmetrically distributed, and the internal force on the left half of the liner structure is relatively large.

4.3. Safety Assessment of Liner Structure. In order to evaluate the safety of liner structure during tunnelling, eccentric distance of various sections can be determined in accordance with relevant provisions $[45,46]$, and then the safety factors of liner structure can be calculated. When $e_{0} \geqslant 0.2 \mathrm{~h}$ ( $h$ is the section height), that is, the eccentric distance of section is larger than the control eccentric distance of section, the calculation section is the large eccentricity compression 

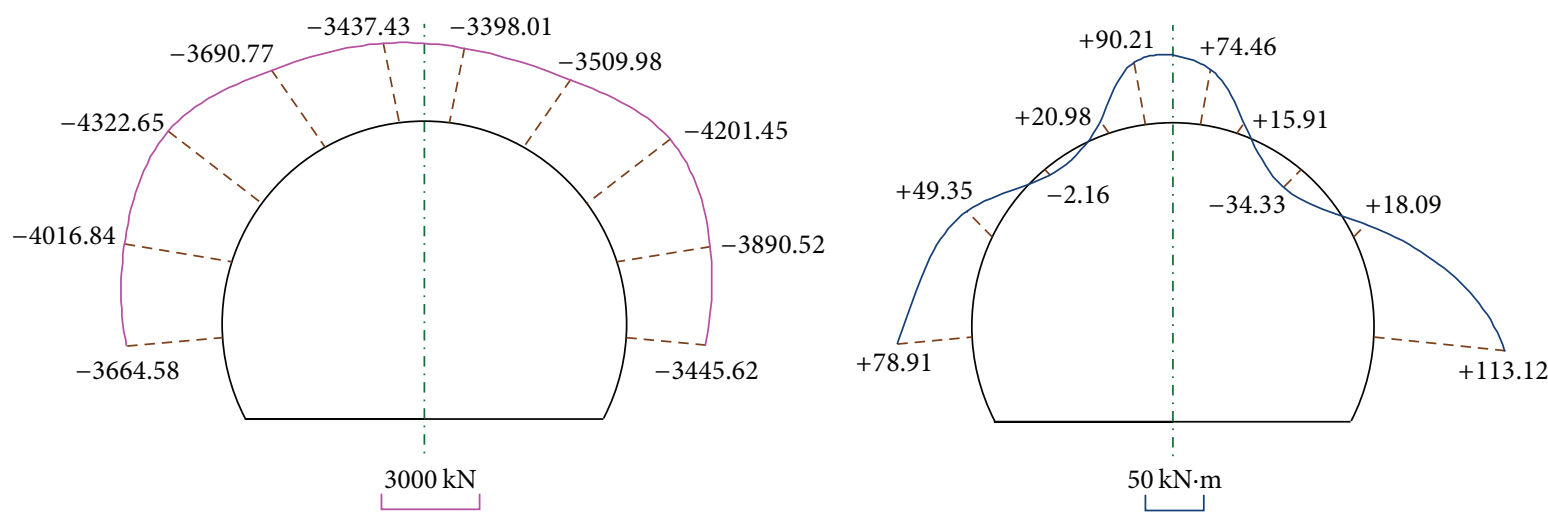

\begin{abstract}
For the axial force distribution, "+" refers to the tension of liner concrete, and "-" means the stress of liner concrete

For the bending moment distribution, "+" represents the tension of liner concrete at the outer side, and "-" stands for the tension of liner concrete at the inner side
\end{abstract}

FIGURE 13: Internal force of the liner structure in the test section.

TABLE 2: Safety factors of the liner structure in each section.

\begin{tabular}{lccccc}
\hline Section & FBG1/FBG6 & FBG2/FBG7 & FBG3/FBG8 & FBG4/FBG9 & FBG5/FBG10 \\
\hline Eccentric distance $(\mathrm{m})$ & 0.022 & 0.004 & 0.007 & 0.005 & 0.003 \\
Eccentric influence factor & 0.996 & 1.000 & 1.000 & 1.000 & 1.000 \\
Compressive stress (MPa) & 8.594 & 9.227 & 10.807 & 10.042 & 9.161 \\
$K$ & 2.8 & 2.62 & 2.24 & 2.41 & 2.64 \\
\hline
\end{tabular}

member. The section bearing capacity is controlled by the tensile strength [47]. Conversely, the calculation section is the axial and small eccentricity compression member and the section bearing capacity is controlled by the compressive strength. Based on the internal force distribution, considering that the internal force on the left side of the liner was basically larger than that on the right side of the liner, the safety assessment of the left side of the liner was performed in this study. And the safety factors of various sections calculated are shown in Table 2.

On the basis of the calculated results listed in Table 2, the eccentric distances of calculation sections are all less than $0.08 \mathrm{~m}$, indicating that the section bearing capacity is controlled by compressive strength. Moreover, the calculated results display that $K$ values of various sections are not less than 2.0 under the composite effects of basic variable load and permanent load, which indicates that the liner structure in the test section is safe, reliable, and stable. Considering the safety factors of all sections, the $K$ value at left vault (FBG1/FBG6) is the maximum, while the $K$ value at left spandrel (FBG3/FBG8) is the minimum. Therefore, the left spandrel is the control section and should be taken as the key monitoring object in the coming years.

\section{Conclusions}

In this study, the stress of the liner concrete was monitored by employing the FBG sensors in the loess tunnel. Also, the temporal stain features of liner concrete and stress behaviors including axial force and bending moment of liner structure were investigated. Based on these analyses, the safety assessment of tunnel liner structure in loess stratum was performed.

(1) Through the calibrations for the FBG sensor, the correlation coefficients of the temperature and strain can be as high as 0.999 after the linear fitting. The change of environment temperature causes the Bragg wavelength shift, which directly impacts the accuracy of the results of strain monitoring. With the decrease of temperature, the wavelength change decreases accordingly, while the wavelength change increases gradually with the temperature increasing. The necessary temperature compensation should be performed.

(2) The compressive stress on the liner concrete has obvious linear characteristics over time in the early stage of monitoring, and the change of concrete strain gets smaller and gradually tends to a certain value after 90th day. The change rate of concrete strain at the outer side of the liner concrete is relatively large. The liner concrete is in pressured state and the stress of monitoring points does not exceed the allowable stress of concrete. The maximum bending moment is $113.12 \mathrm{kN} \cdot \mathrm{m}$, which is located at the sidewall of the tunnel. 
(3) FBG monitoring data and safety assessment results indicate that the safety factors of various liner sections all meet the code requirements. And the $K$ value at left vault is the maximum, while the $K$ value at left spandrel is the minimum. Moreover, FBG sensorsbased in situ monitoring subsequently can also verify the safety and stability of the tunnel liner structure.

(4) FBG sensors-based in situ monitoring on the internal force of the loess tunnel structure is of great environmental adaptability and performance stability. However, considering the cross effects of uncertain factors, such as special engineering properties of the loess, hydration heat of cement, and shrinkage and creep of concrete, the strain collected through FBG sensors is influenced by composite factors. The stress and strain of liner concrete under the independent action of various factors cannot be analyzed accurately by using current ways. Therefore, it is necessary to conduct relevant studies to solve the cross effect problems.

\section{Competing Interests}

The authors declare that there is no conflict of interests regarding the publication of this paper.

\section{Acknowledgments}

This work is financially supported by the Brainstorm Project on Social Development of Shaanxi Provincial Science and Technology Department (no. 2016SF-412), the Industrial Research Project of Science and Technology Department of Shaanxi Province (no. 2015GY185), the Special Fund for Basic Scientific Research of Central Colleges of Chang'an University (no. 310821165011), the Applied Basic Research Project (main subject) of the Ministry of Transport of the People's Republic of China (no. 2015319812 140), and the Collaborative Innovation Project of Shaanxi Province (no. 2015XT-33). The authors would like to express appreciation to the reviewers for their valuable comments and suggestions that helped to improve the quality of the paper.

\section{References}

[1] D. Dias and R. Kastner, "Movements caused by the excavation of tunnels using face pressurized shields-analysis of monitoring and numerical modeling results," Engineering Geology, vol. 152, pp. 17-25, 2013.

[2] F. Dai, M.-W. Park, M. Sandidge, and I. Brilakis, "A vision-based method for on-road truck height measurement in proactive prevention of collision with overpasses and tunnels," Automation in Construction, vol. 50, pp. 29-39, 2015.

[3] J. X. Lai, J. L. Qiu, J. X. Chen, H. B. Fan, and K. Wang, "New technology and experimental study on snow-melting heated pavement system in tunnel portal," Advances in Materials Science and Engineering, vol. 2015, Article ID 706536, 11 pages, 2015.

[4] P. Olaszek, "Investigation of the dynamic characteristic of bridge structures using a computer vision method," Measurement, vol. 25, no. 3, pp. 227-236, 1999.
[5] A. M. Wahbeh, J. P. Caffrey, and S. F. Masri, "A vision-based approach for the direct measurement of displacements in vibrating systems," Smart Materials and Structures, vol. 12, no. 5, pp. 785-794, 2003.

[6] C. K. Y. Leung, K. T. Wan, D. Inaudi et al., "Review: optical fiber sensors for civil engineering applications," Materials and Structures, vol. 48, no. 4, pp. 871-906, 2015.

[7] P. Ferdinand, O. Ferragu, J. L. Lechien et al., "Mine operating accurate STABILity control with optical fiber sensing and bragg grating technology: The European BRITE/EURAM STABILOS Project," Journal of Lightwave Technology, vol. 13, no. 7, pp. 13031313, 1995.

[8] R. Hadzic, S. John, and I. Herszberg, "Structural integrity analysis of embedded optical fibres in composite structures," Composite Structures, vol. 47, no. 1-4, pp. 759-765, 1999.

[9] P. Ferraro and G. De Natale, "On the possible use of optical fiber Bragg gratings as strain sensors for geodynamical monitoring," Optics and Lasers in Engineering, vol. 37, no. 2-3, pp. 115-130, 2002.

[10] J. Leng and A. Asundi, "Structural health monitoring of smart composite materials by using EFPI and FBG sensors," Sensors and Actuators A: Physical, vol. 103, no. 3, pp. 330-340, 2003.

[11] B. Lee, "Review of the present status of optical fiber sensors," Optical Fiber Technology, vol. 9, no. 2, pp. 57-79, 2003.

[12] M. Majumder, T. K. Gangopadhyay, A. K. Chakraborty, K. Dasgupta, and D. K. Bhattacharya, "Fibre Bragg gratings in structural health monitoring-present status and applications," Sensors and Actuators A: Physical, vol. 147, no. 1, pp. 150-164, 2008.

[13] S. Zheng, "Long-period fiber grating moisture sensor with nano-structured coatings for structural health monitoring," Structural Health Monitoring, vol. 14, no. 2, pp. 148-157, 2015.

[14] R. K. Ramalingam, R. Nast, and H. Neumann, "Fiber bragg grating sensors for distributed torsional strain measurements in a (RE) BCO tape," IEEE Sensors Journal, vol. 15, no. 4, pp. $2023-$ 2030, 2015.

[15] Z. Y. Cai, F. Liu, T. Guo, B. O. Guan, G. D. Peng, and J. Albert, "Evanescently coupled optical fiber refractometer based a tilted fiber Bragg grating and a D-shaped fiber," Optics Express, vol. 23, no. 16, pp. 20971-20976, 2015.

[16] A. Mendez, T. F. Morse, and F. Mendez, "Applications of embedded optical fiber sensors in reinforced concrete buildings and structures," in Proceedings of the Fiber Optic Smart Structures and Skins II, vol. 1170 of Proceedings of SPIE, pp. 60-69, Boston, Mass, USA, September 1990.

[17] Y. Zhang, D. Feng, Z. Liu et al., "High-sensitivity pressure sensor using a shielded polymer-coated fiber Bragg grating," IEEE Photonics Technology Letters, vol. 13, no. 6, pp. 618-619, 2001.

[18] R. Di Sante, L. Donati, E. Troiani, and P. Proli, "Evaluation of bending strain measurements in a composite sailboat bowsprit with embedded fibre Bragg gratings," Measurement, vol. 54, pp. 106-117, 2014.

[19] R. M. Measures, A. T. Alavie, R. Maaskant, M. Ohn, S. Karr, and S. Huang, "Structurally integrated Bragg grating laser sensing system for a carbon fiber prestressed concrete highway bridge," Smart Materials and Structures, vol. 4, no. 1, pp. 20-30, 1995.

[20] D. C. Betz, L. Staudigel, M. N. Trutzel, and M. Kehlenbach, "Structural monitoring using fiber-optic bragg grating sensors," Structural Health Monitoring, vol. 2, no. 2, pp. 145-152, 2003.

[21] M. Sun, W. J. Staszewski, and R. N. Swamy, "Smart sensing technologies for structural health monitoring of civil engineering 
structures," Advances in Civil Engineering, vol. 2010, Article ID 724962, 13 pages, 2010.

[22] X. W. Ye, Y. Q. Ni, and J. H. Yin, "Safety monitoring of railway tunnel construction using FBG sensing technology," Advances in Structural Engineering, vol. 16, no. 8, pp. 1401-1409, 2013.

[23] X. W. Ye, Y. H. Su, and J. P. Han, "Structural health monitoring of civil infrastructure using optical fiber sensing technology: a comprehensive review," Scientific World Journal, vol. 2014, Article ID 652329, 11 pages, 2014.

[24] J. X. Lai, H. B. Fan, J. X. Chen, J. L. Qiu, and K. Wang, "Blasting vibration monitoring of undercrossing railway tunnel using wireless sensor network," International Journal of Distributed Sensor Networks, vol. 2015, Article ID 703980, 7 pages, 2015.

[25] N. Tondini, O. S. Bursi, A. Bonelli, and M. Fassin, "Capabilities of a fiber bragg grating sensor system to monitor the inelastic response of concrete sections in new tunnel linings subjected to earthquake loading," Computer-Aided Civil and Infrastructure Engineering, vol. 30, no. 8, pp. 636-653, 2015.

[26] A. Lönnermark, P. O. Hedekvist, and H. Ingason, "Gas temperature measurements using fibre Bragg grating during fire experiments in a tunnel," Fire Safety Journal, vol. 43, no. 2, pp. 119-126, 2008.

[27] C. Li, Y.-G. Zhao, H. Liu, Z. Wan, C. Zhang, and N. Rong, "Monitoring second lining of tunnel with mounted fiber Bragg grating strain sensors," Automation in Construction, vol. 17, no. 5, pp. 641-644, 2008.

[28] N. Roveri, A. Carcaterra, and A. Sestieri, "Real-time monitoring of railway infrastructures using fibre Bragg grating sensors," Mechanical Systems and Signal Processing, vol. 60, pp. 14-28, 2015.

[29] X. Weng, J. Chen, and J. Wang, "Fiber Bragg grating-based performance monitoring of piles fiber in a geotechnical centrifugal model test," Advances in Materials Science and Engineering, vol. 2014, Article ID 659276, 8 pages, 2014.

[30] X. Weng, H. Ma, and J. Wang, "Stress monitoring for anchor rods system in subway tunnel using FBG technology," Advances in Materials Science and Engineering, vol. 2015, Article ID 480184, 7 pages, 2015.

[31] X. Weng, Y. Nie, and J. Lu, "Strain monitoring of widening cement concrete pavement subjected to differential settlement of foundation," Journal of Sensors, vol. 2015, Article ID 679549, 7 pages, 2015.

[32] W. Cheng, W. Wang, S. Huang, and P. Ma, "Acoustic emission monitoring of rockbursts during TBM-excavated headrace tunneling at Jinping II hydropower station," Journal of Rock Mechanics and Geotechnical Engineering, vol. 5, no. 6, pp. 486494, 2013.

[33] Micron Optics Inc, sm125 Optical Sensing Interrogator, Product Manual and Technical Reference, Micron Optics Inc, Atlanta, Ga, USA, http://www.micronoptics.com.

[34] J. Lai, S. Mao, J. Qiu et al., "Investigation progresses and applications of fractional derivative model in geotechnical engineering," Mathematical Problems in Engineering, vol. 2016, Article ID 9183296, 15 pages, 2016.

[35] J. Lai, J. Qiu, Z. Feng, J. Chen, and H. Fan, "Prediction of soil deformation in tunnelling using artificial neural networks," Computational Intelligence and Neuroscience, vol. 2016, Article ID 6708183, 16 pages, 2016.

[36] B. Yang, L. Zhang, E. Liu, J. Dong, H. Zhu, and Y. Chen, "Deformation monitoring of geomechanical model test and its application in overall stability analysis of a high arch dam," Journal of Sensors, vol. 2015, Article ID 470905, 12 pages, 2015.
[37] K. O. Hill, Y. Fujii, D. C. Johnson, and B. S. Kawasaki, "Photosensitivity in optical fiber waveguides: application to reflection filter fabrication," Applied Physics Letters, vol. 32, no. 10, pp. 647-649, 1978.

[38] G. Meltz, W. W. Morey, and W. H. Glenn, "Formation of Bragg gratings in optical fibers by a transverse holographic method," Optics Letters, vol. 14, no. 15, pp. 823-825, 1989.

[39] J.-L. Archambault, L. Reekie, and P. St. J. Russell, "100\% Reflectivity Bragg reflectors produced in optical fibres by single excimer laser pulses," Electronics Letters, vol. 29, no. 5, pp. 453455, 1993.

[40] W. W. Morey, G. Meltz, and W. H. Glenn, "Bragg-grating temperature and strain sensors," in Optical Fiber Sensors, Springer Proceedings in Physics, pp. 526-531, Springer, Berlin, Germany, 1989.

[41] M. Majumder, T. K. Gangopadhyay, A. K. Chakraborty, K. Dasgupta, and D. K. Bhattacharya, "Fibre Bragg gratings in structural health monitoring-Present status and applications," Sensors and Actuators, A: Physical, vol. 147, no. 1, pp. 150-164, 2008.

[42] F. Xie, S. L. Zhang, Y. Li, and S. B. Lee, "Temperaturecompensating multiple fiber Bragg grating strain sensors with a metrological grating," Optics and Lasers in Engineering, vol. 41, no. 1, pp. 205-216, 2004.

[43] H. S. Shi and X. Y. Huang, "Research progress of hydration heat in cement and concrete," Cement Technology, vol. 6, pp. 21-26, 2009.

[44] J. X. Lai, K. Y. Wang, J. L. Qiu, F. Y. Niu, J. B. Wang, and J. X. Chen, "Vibration response characteristics of the cross tunnel structure," Shock and Vibration, In press.

[45] JTG D70-2004 Code for Design of Road Tunnel, China Communication Press, Beijing, China, 2004.

[46] L. Gong, K. G. Sun, and W. G. Qiu, "Study of the force characteristics of the primary support in a tunnel with large deformation and related countermeasures," Modern Tunnelling Technology, vol. 49, no. 6, pp. 70-74, 2012.

[47] Z. Zhu, S. German, and I. Brilakis, "Visual retrieval of concrete crack properties for automated post-earthquake structural safety evaluation," Automation in Construction, vol. 20, no. 7, pp. 874-883, 2011. 


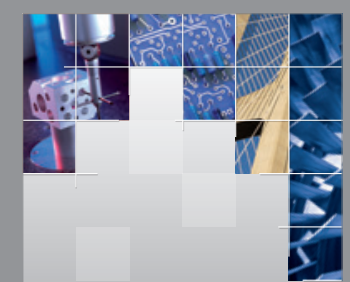

\section{Enfincering}
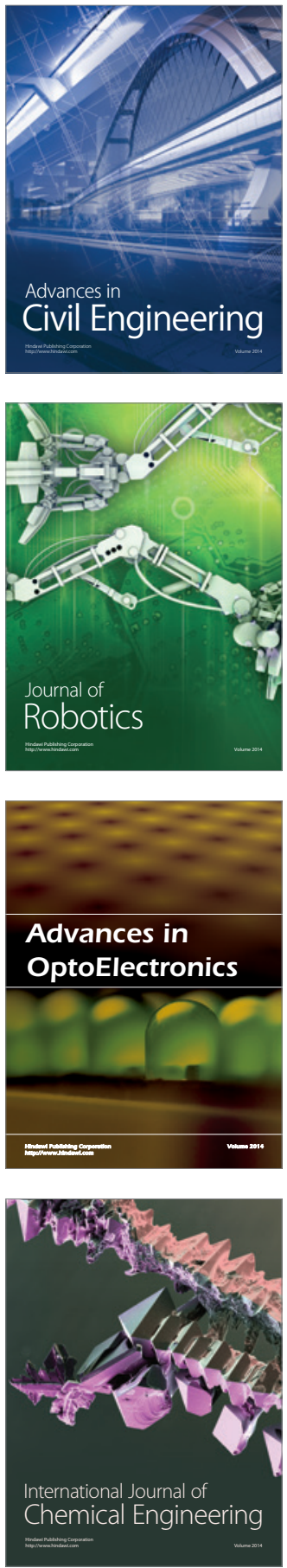

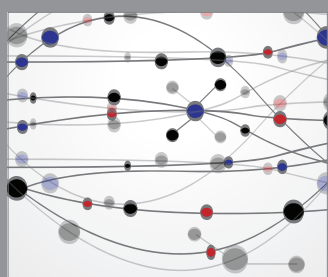

The Scientific World Journal

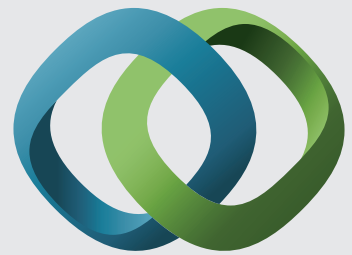

\section{Hindawi}

Submit your manuscripts at

http://www.hindawi.com
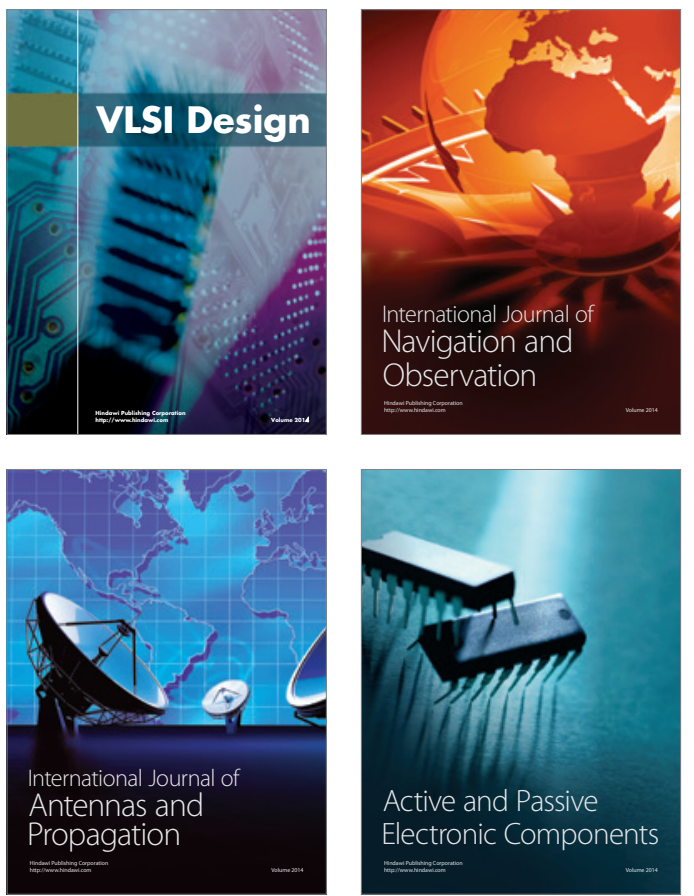
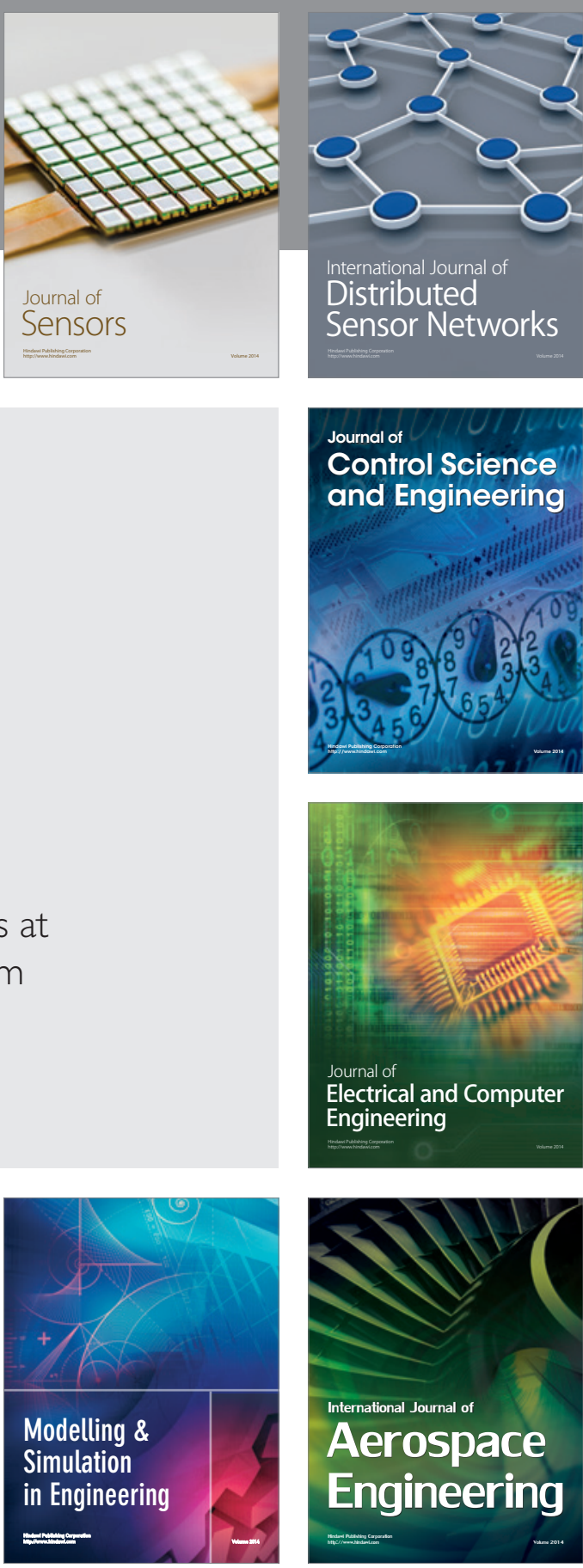

International Journal of

Distributed

Sensor Networks

Journal of

Control Science

and Engineering
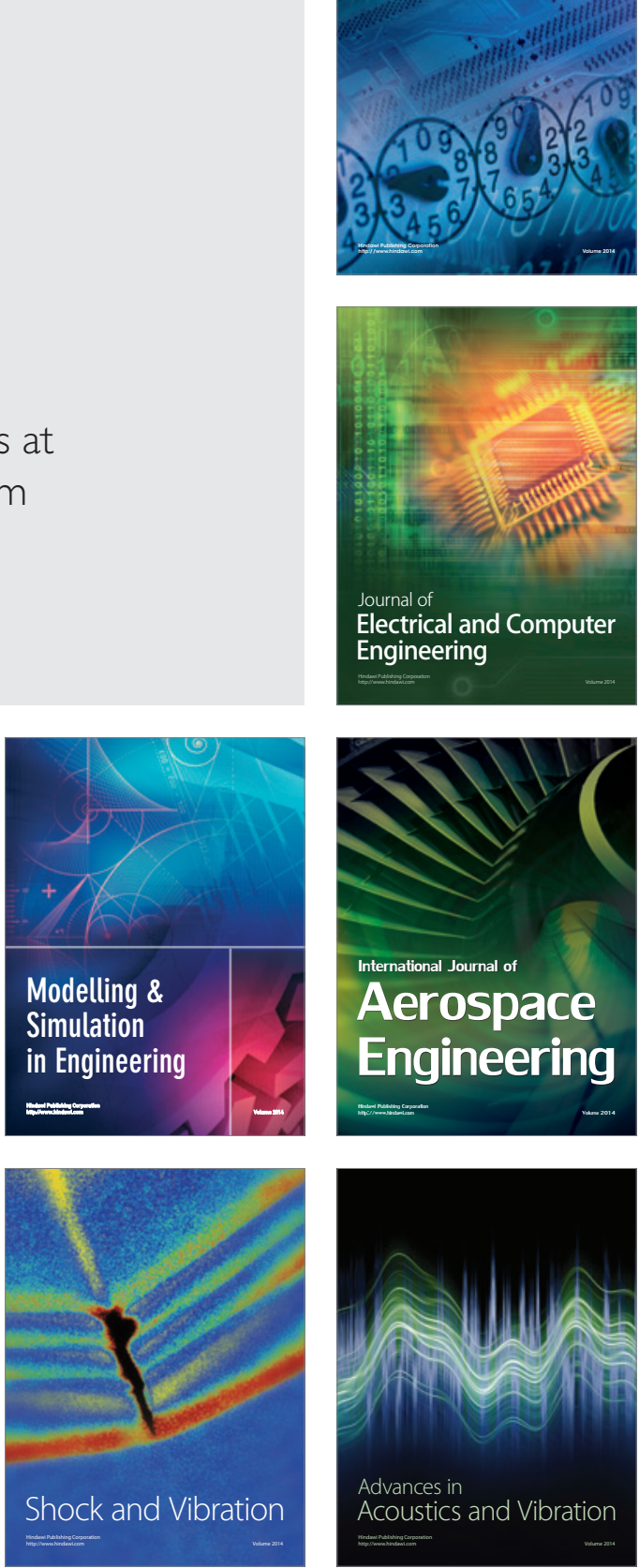